
\title{
СТРУКТУРАЛИЗМ И СОЦИАЛЬНАЯ АНТРОПОЛОГИЯ В ТРУДАХ БРИТАНСКИХ ИССЛЕДОВАТЕЛЕЙ ХХ ВЕКА
}

\section{STRUCTURALISM AND SOCIAL ANTHROPOLOGY IN THE WORKS OF BRITISH SCIENTISTS OF THE 2OTH CENTURY}

\section{Ju. Gavrilova}

Summary: The article deals with looking into basic ideas of British linguists and anthropologists whose works actually combined both disciplines. The author begins the overview by the ideas of B. Malinowski, famous anthropologist and linguist. He introduced the notion "context of situation", which later was widely employed in linguistics. Then the author provides the reader with information about E. Leach and R. Needham and proves the connection between both scientific disciplines.

Keywords: anthropology, linguistics, context of situation, structure, theory, social organization, kinship terms.
Гаврилова Юлия Викторовна

К.филол.н., дочент, Московский гуманитарный университет March1378@yandex.ru

Аннотация: Статья посвящена рассмотрению основных идей британских лингвистов и антропологов, чьи работы были написаны на стыке двух дисциплин. Автор начинает свой обзор с взглядов Б. Малиновского, известного антрополога и лингвиста. Им было введено в науку понятие «контекст ситуации», впоследствии широко применимое в языкознании. Далее автор знакомит читателя с идеями Э. Лича и Р. Нидхэма, доказывая на примере их концепций взаимосвязь научных дисциплин.

Ключевые слова: антропология, лингвистика, контекст ситуации, структура, теория, социальная организация, термины родства.
$\mathrm{B}$ ольшинство людей, услышав названия таких наук, как антропология и языкознание, скорее всего, воспримут их как самостоятельные отдельные отрасли научного знания и, более того, вряд ли тесно связанные друг с другом.

Однако в данной статье нам хотелось бы познакомить читателя с трудами лингвистов, успешно сочетавших в карьере исследования по антропологии и языкознанию и показать имевшую место в указанный исторический период взаимосвязь и взаимозависимость данных двух направлений, сосуществовавших в Великобритании и успешно дополнявших друг друга.

Итак, начать хотелось бы с научных взглядов известного британского антрополога польского происхождения Бронислава Малиновского (Bronislaw Kasper Malinowski, 1884-1942). По своей сути концепция Малиновского - это теория, разработанная прежде всего антропологом и этнографом, который только впоследствии обратился к языкознанию.

Принято считать, что Малиновский увлекся антропологией после прочтения книги Дж. Фрезера «Золотая ветвь». Полевые исследования Малиновский проводил в основном в Меланезии. В отличие от других исследователей первобытных племён, антрополог Малиновский жил среди туземцев и лично знакомился с их бытом и языком. Именно разработанный в тот период его метод включённого наблюдения теперь является одним из ключевых методов исследований в антропологии.

Однако естественно, что зачастую бывает невозможно глубоко и всесторонне изучить культуру и традиции того иного народа без знания языка, на котором ежедневно общаются люди. Поэтому Малиновский, конечно, проявлял интерес не только к полевой работе с туземцами, но и к изучению их языка.

Первая книга антрополога Малиновского "Classificatory Particles in the Language of Kiriwina" [3], вышедшая в 1920 году, была посвящена грамматическим категориям частиц в языке киривина (язык жителей Тробрианских островов), то есть собственно лингвистическим вопросам. Также неоднократно отмечалась необходимость разработки такой семантической теории, которая смогла бы дать возможность языковедам глубже исследовать структуру языка и объяснять грамматические факты, так как семантическая теория должна быть тесно связана с этнографической, а понимание того, о чём говорят люди, напрямую зависит от их культурной принадлежности. Таким образом, по его мнению, без семантической теории невозможно проведение грамматического анализа.

Лингвистический термин контекст ситуации, как мы знаем, был введен в лингвистическую науку именно Малиновским, а впоследствии он нашёл широкое применение в работах других языковедов популярного в XX веке структурного направления и в том числе в теории 
лингвистов - «Лондонцев». Поэтому получается, что антропологический термин оказался вполне применимым в лингвистическом структурализме.

Малиновский предпринял попытку показать, как употребление языка может быть связано с социальным и эмоциональным контекстами. Исследователем также были сформулированы универсальные грамматические категории: местоимения, прилагательные, наречия, союзы, некоторые падежи существительных, включая именительный, притяжательный, объектный, предложный.

Спустя 12 лет, в 1935 году, была опубликована заключительная работа "Coral Gardens and their Magic" [4], где была подробно изложена семантическая теория, основанная на идее о том, что значение высказываний обеспечивается контекстом окружающей их человеческой деятельности. Были изложены три новых ключевых принципа теории:

1. высказывание в контексте ситуации - основа лингвистических исследований;

2. если какой-то звук употреблён в двух разных контекстах, то его нельзя считать одним и тем же словом, а следует рассматривать как два;

3. контекст ситуации может решить проблему семантической двойственности некоторых предложений.

Важно отметить, что язык всегда понимался Малиновским как аспект культуры и как одна из важнейших форм человеческой деятельности. Язык - средство социальной деятельности человека. Таким образом, концепция учёного совмещала в себе данные и методы антропологии, культурологии, социологии и лингвистики и оказала влияние на развитие целого ряда смежных дисциплин.

Другой британский социальный антрополог, работавший в более поздний период, о котором пойдет речь ниже, это сэр Эдмунд Рональд Лич (Edmund Ronald Leach, 1910-1989). В данной статье мы не можем не упомянуть работы этого исследователя, так как они непосредственно тесно связаны с идеями Бронислава Малиновского. А именно, Малиновский руководил диссертационной работой Лича в ходе его обучения в Лондонской школе экономических и политических наук. Защита состоялась в 1947 году, а работа была написана на материале полевых исследований, проведённых в Бирме еще до начала II мировой войны.

Как пишет Я.В. Чеснов в сопроводительной статье к труду Эдмунда Лича 1976 года, «Эдмунд Лич на своей родине был известен не только специалистам-антропологам. ... Его творчество отвечало общественному интересу ко всеобщим условиям человеческого существования. Лич занимался тем, что в широком смысле можно назвать экологией человека. Для этого он привлекал методы естественных и социальных наук, а также философии» [1].

Необходимо упомянуть в данной связи одну из важнейших для нашего исследования работ Лича «Культура и коммуникация: логика взаимосвязи символов. К использованию структурного анализа в социальной антропологии» [2], вышедшую в 1976 году, так как ее содержание как раз и демонстрирует связь структурного анализа и антропологии.

Книга посвящена рассмотрению с позиций структурного анализа проблем терминологии, теории магии и колдовства, различных предписаний и запретов, а также вопросов мифологии. В 2001 году книга была издана на русском языке в рамках книжной серии «Этнографическая библиотека», таким образом, русскоязычные читатели получили доступ к этому замечательному произведению.

Лич отмечает: «Мой главный тезис...: культура осуществляет коммуникацию; сама по себе сложная взаимосвязь культурных событий передаёт информацию тем, кто в этих событиях участвует. Исходя из этого моя цель состоит в том, чтобы предложить систематическую процедуру, посредством которой антрополог, пользующийся методикой «включенного наблюдения», может приступить к расшифровке посланий, содержащихся в наблюдаемых им сложных объектах» $[2$, с. 7].

Сама книга написана в форме эссе для студентов и в ней, соответственно, даются толкования задач, функций и методов работы социальных антропологов. Так, «по мысли социальных антропологов-рационалистов (структуралистов), структура системы социальных представлений имеет такое же отношение к тому, что происходит в реальности, какое партитура имеет к ее исполнению...Рационалисты стремятся писать о культурных системах как о созданиях своего рода коллективного «человеческого сознания» [2, с.12]. То есть структурализм как направление существовал, как нам известно, не только в языкознании, но и в ряде других наук, в том числе в антропологии.

Нельзя обойти вниманием другую замечательную фигуру британской социальной антропологии XX века, Родни Нидхэма (Rodney Needham, 1923-2006). Газета «Индепендент» в некрологе от 13 декабря 2006 года назвала его «оксфордским социальным антропологом и чемпионом структурализма» [8]. Он был ведущим социальным антропологом своей эпохи, который вместе с Эдмундом Личем и Мэри Дуглас (Mary Douglas, 1921-2007, известной работами по культуре и символизму), внес заметный вклад в развитие британской социальной антропологии. Сферой научных интересов Нидхэма было исследование социальной организации общества, терминов родства и 
систем символической классификации.

Пользуясь структурным подходом и доказывая его большую эффективность по сравнению с психологическим подходом, он изучал систему социальной организации и термины родства в небольших обществах. Руководителем выпускной работы Нидхэма, которую он защитил в 1950 году, был известный антрополог Рэдклифф-Браун. С 1956 года и в течение всей карьеры он преподавал социальную антропологию в Оксфордском университете. Первым значительным трудом принято считать книгу «Структура и чувство» (Structure and Sentiment, 1962 года). Среди других работ можно назвать: "Remarks and Inventions" [6], "Circumstantial Deliveries" [5].

Таким образом, мы видим, что структурный анализ в исследованиях британских ученых был неразрывно связан с антропологией, а изучение терминов родства в антропологии было невозможно, в свою очередь, без обращения к идеям и принципам лингвистической науки.

\section{ЛИТЕРАТУРА}

1. Чеснов Я.В. От коммуникации к культуре, или зачем сэру Эдмунду Личу нужно понять другого человека // Leach E.R. Culture and Communication: the logic by which symbols are connected. An introduction to the use of structuralist analysis in social anthropology, 1976. Электронный pecypc [http://cult-lib.ru/doc/ culture/communication/023.htm]

2. Leach E.R. Culture and Communication: the logic by which symbols are connected. An introduction to the use of structuralist analysis in social anthropology, 1976. Электронный ресурс [http://cult-lib.ru/doc/culture/communication/023.htm]

3. Malinowski B. Classificatory Particles in the Language of Kiriwina // Bulletin of the School of Oriental and African Studies. - London, 1920. Vol. 1, Part 4. - P.33-78.

4. Malinowski B. Coral Gardens and their Magic. Vol.2: the Language of Magic and Gardening. - London: George Alien and Unwin Ltd., 1966. - 350 p.

5. Needham R. Circumstantial Deliveries. Berkeley: University of California Press, 1981.

6. Needham R. Remarks and Inventions: Skeptical Essays about Kinship. London: Tavistock Publications, 1974.

7. Родни Нидхэм. Биография и основные работы (электронный ресурс) [https://www.researchgate.net/publication/327454016_Needham_ Rodney_1923-2006/link/5f373dec458515b729220a59/download]

8. Rodney Needham. Obituary (электронный ресурс) [https://www.independent.co.uk/news/obituaries/rodney-needham-428191.html]

(с Гаврилова Юлия Викторовна (March1378@yandex.ru).

Журнал «Современная наука: актуальные проблемы теории и практики»

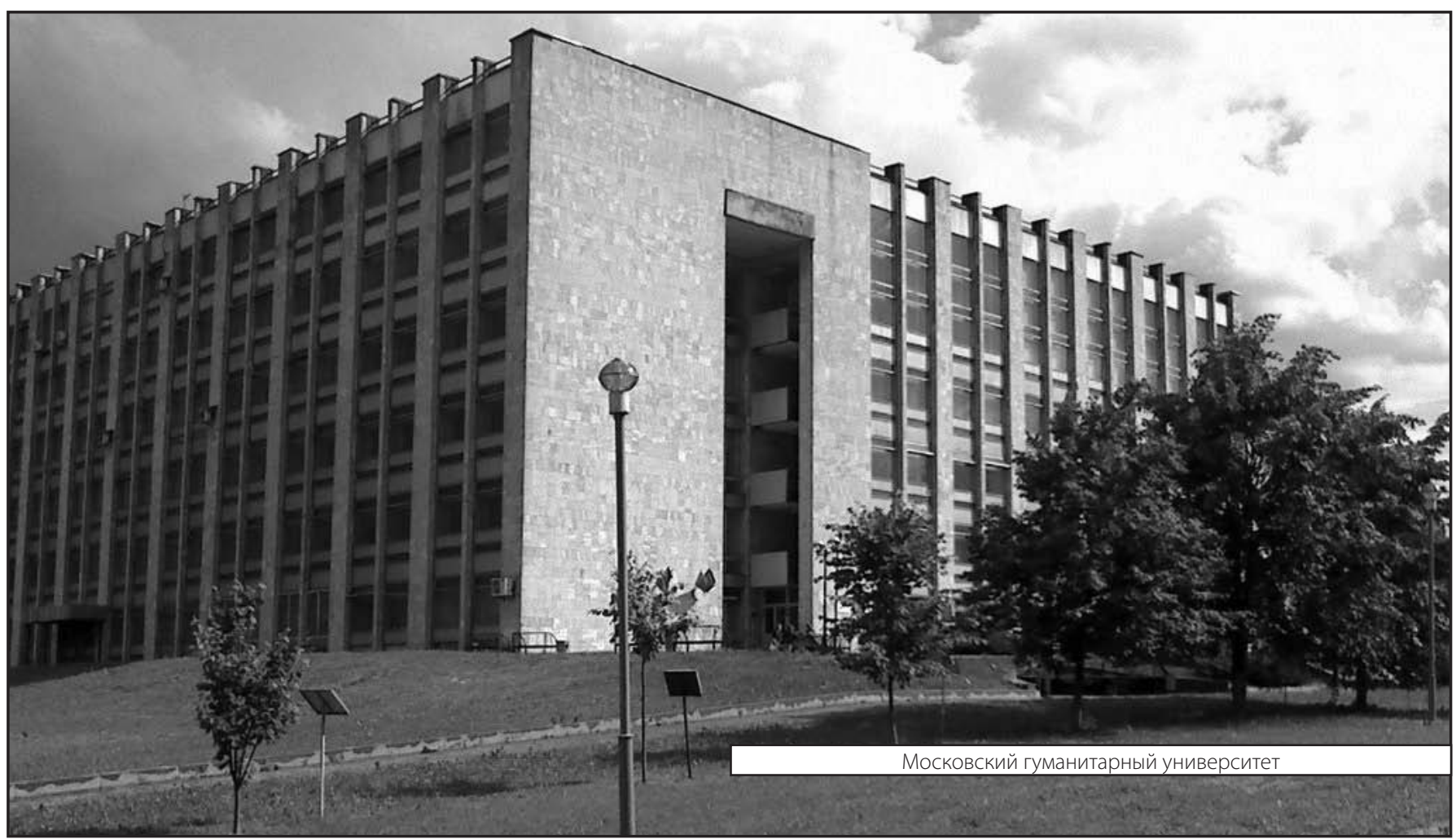

